\title{
Outcomes of Facial Nerve in Lateral and Inferior Mastoid Approaches for Jugular Foramen and Petrous Apex Lesions
}

\author{
Saurin Shah ${ }^{1}$ Amit Keshri ${ }^{1}$ Simple Patadia ${ }^{1} \quad$ Rabi Narayan Sahu $^{1} \quad$ Raj Kumar $^{1}$ \\ ${ }^{1}$ Department of Neurosurgery, Sanjay Gandhi Postgraduate Institute \\ of Medical Sciences, Lucknow, Uttar Pradesh, India

\begin{abstract}
Address for correspondence Amit Keshri, MS, ENT, Department of Neurosurgery, Sanjay Gandhi Postgraduate Institute of Medical Sciences, C Block, Lucknow 226014, Uttar Pradesh, India (e-mail: amitkeshri2000@yahoo.com).
\end{abstract}

Indian J Neurosurg 2018;7:23-28

\begin{abstract}
Objectives To evaluate the facial nerve in inferior and lateral (transmastoid) approaches to the jugular foramen and/or petrous apex.

Design Retrospective study of 11 consecutive patients operated for lesions in the jugular foramen/petrous apex via an inferior or lateral transpetrosal approach.

Setting Tertiary care superspecialty referral center.

Participants Eleven consecutive patients of jugular foramen/petrous apex lesions operated over a period of 18 months.

Main Outcomes Measures Extent of tumor resection, surgical technique used, and recovery of facial nerve function postoperatively.

Keywords

- facial nerve

Conclusion Approach to these lesions needs to be tailored to the extent of disease,

- jugular foramen possible histology and relation to the facial nerve. Meticulous surgery and adequate postoperative care permit a satisfactory recovery of facial nerve function following

- petrous apex rerouting procedures.
\end{abstract}

\section{Introduction}

Access to the petrous apex and jugular foramen has always been a surgical challenge because of compactly organized critical neurovascular structures. The area has been traditionally accessed by neurosurgical corridors directed either superiorly (middle fossa approaches, anterior petrosectomy) or posteriorly (retromastoid, suboccipital). Neuro-otologic procedures established to access the lesions located in this region provide a trajectory directed inferiorly (infratemporal fossa approaches-Fisch $\mathrm{A} / \mathrm{B} / \mathrm{C}$ ) or laterally (posterior petrosectomy, translabyrinthine/transcochlear/transotic).

These approaches are modified as determined by the disease extent and best addressed by a team comprising both neurosurgeons and neuro-otologists for favorable outcomes. The aim of surgery and likelihood of neurovascular preservation are also important factors to be considered for deciding the surgical approach. The goal of surgery in modern neuro-otology remains neurovascular preservation even at the expense of tumor removal, especially for benign lesions.

received

October 29, 2016 accepted after revision

July 3, 2017

published online

April 10, 2018
The mastoid segment of the facial nerve occupies the center of the operative field in the infratemporal fossa or laterally directed approaches and is placed lateral to the jugular bulb ${ }^{1}$ (-Fig. 1). For inferolateral approaches, the extent of surgical exposure possible depends on the management of the facial nerve during surgery, viz. retrofacial/extended facial recess/ facial nerve rerouting approach. ${ }^{2}$

The intrinsic blood supply to the facial nerve allows recovery of function even when the extrinsic blood supply is compromised during surgical manipulation for rerouting procedures. The House-Brackmann (HB) classification $(\mathrm{I}-\mathrm{VI})^{3}$ is used to assess facial nerve function (gross and motor). Short (second genu to parotid) and long (first genu to parotid) segment reroutings are traditionally associated with long-term outcomes reported as HB grade I-II and II-IV, respectively. The Makek grading (I-IV) ${ }^{1}$ is used to describe facial nerve involvement by the tumor intraoperatively. Preoperative facial nerve dysfunction remains an independent adverse risk factor for recovery of facial nerve function.

Copyright @2018 Neurological

License terms

Surgeons' Society of India 


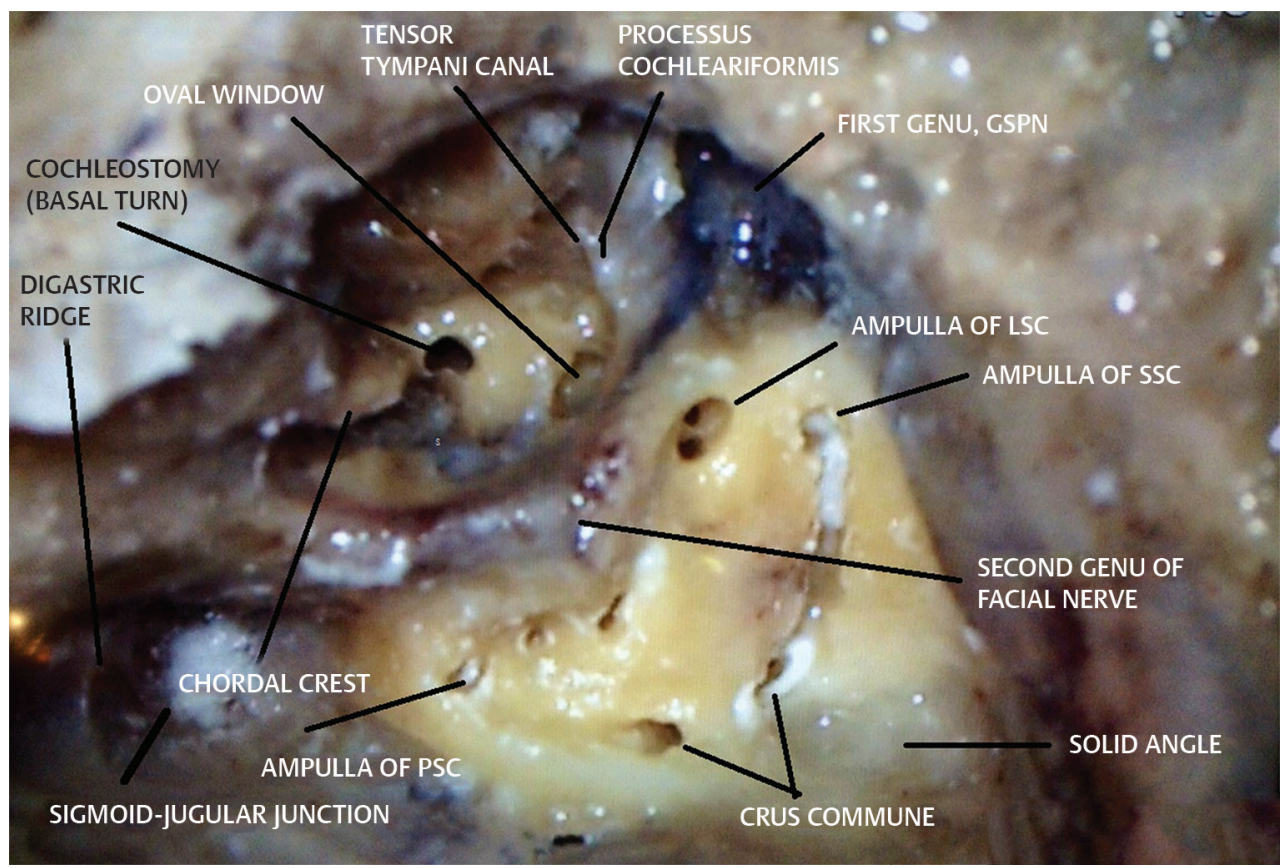

Fig. 1 Left temporal bone dissection specimen. GSPN, greater superficial petrosal nerve; LSC, lateral semicircular canal; PSC, posterior semicircular canal; SSC, superior semicircular canal.

Literature abounds in controversy regarding management and outcomes pertaining to facial nerve rerouting and function recovery when managing these complex lesions. The purpose of this study is to highlight the possible surgical options related to the facial nerve and the favorable outcome with facial nerve rerouting by combined neuro-otology and neurosurgery team. We have also tried to evaluate facial nerve rerouting as a possible alternative to the classic neurosurgical approaches, in which facial nerve management becomes challenging as it comes in surgical field and is more prone to injury, hindering complete excision of lesion in totality.

\section{Materials and Methods}

A retrospective systematic review of 11 consecutive cases of petrous apex and/or jugular foramen-based lesion operated via an inferior or lateral approach between April 2014 and December 2015 was done.

\section{Inclusion Criteria}

1. Diagnosis of jugular foramen and/or petrous apex mass based on imaging (computed tomography [CT]/magnetic resonance imaging (MRI)/both)

2. Informed and written consent available for preoperative transarterial embolization, surgery, and use of data in scientific forums/for research purposes

3. Histopathologically proven diagnosis from the surgical specimen

4. Availability of operative procedure findings and events during hospital stay available for review

5. Postoperative contrast-enhanced CT scan done within 72 hours of surgery and then a CT/MR done at 3-month follow-up
6. Minimum 6-month follow-up in cases with facial nerve dysfunction

Fifteen out of 20 cases operated during this period qualified the inclusion criteria. Five cases of glomus tympanicum (limited to the middle ear cleft) operated during this period were excluded from this study.

In cases with suspected vascular tumor, a preoperative transarterial embolization of the external carotid artery territory feeders was done using polyvinyl alcohol (PVA) or Gelfoam particles up to 72 hours prior to surgery.

\section{Surgery}

A C-shaped incision is placed approximately 2.5 to $3 \mathrm{~cm}$ behind the postaural grove in continuity with a neck incision placed in the natural skin crease at the level of the hyoid bone. Subperiosteal dissection is done over the cranium, and subplatysmal flaps are elevated in the neck. Control of major neck vessels is obtained. Cul-de-sac closure of the external auditory canal (EAC) is necessary as the operative defect in the mastoid does not allow natural mucosal drainage through the eustachian tube. It also avoids infection in the operated field. ${ }^{4}$ Further exposure of the jugular foramen/petrous apex region is determined by the tumor location, suspected pathology, aim of surgery, and neurovascular status of the patient prior to surgery. Intraoperative frozen section histology is routinely obtained to modify the surgical plan if necessary.

\section{Canal Wall Down Mastoidectomy}

One case of paraganglioma involving the jugular bulb and extending into the mastoid tip was operated via conventional canal wall down (CWD) mastoidectomy surgery without facial nerve rerouting or cul-de-sac closure of the EAC. 


\section{Extended Facial Recess Approach}

A patient with adenoma (benign lesion on intraoperative frozen section) involving the jugular bulb, petrous apex, and mastoid cavity was operated by a canal wall up mastoidectomy followed by a facial recess approach to clear disease from the region surrounding the facial canal, middle ear, and jugular bulb. The facial nerve was decompressed in the region of second genu and mastoid segment ( - Fig. 2).

\section{Presigmoid Retrofacial (Infralabyrinthine) Approach}

Five out of 15 patients in our series were operated via a canal wall up mastoidectomy followed by clearance of disease medial to the vertical (mastoid) segment of the facial nerve. Depending on the extent of disease, the jugular vein was exposed in the neck if required.

\section{Infratemporal Fossa Fisch A Approach}

For glomus tumors (Fisch stage $C / D$ ), infratemporal fossa approach was most commonly chosen. Depending on the extent of the lesion, the facial nerve was rerouted (transposed) in its short or long segment. A cul-de-sac closure of

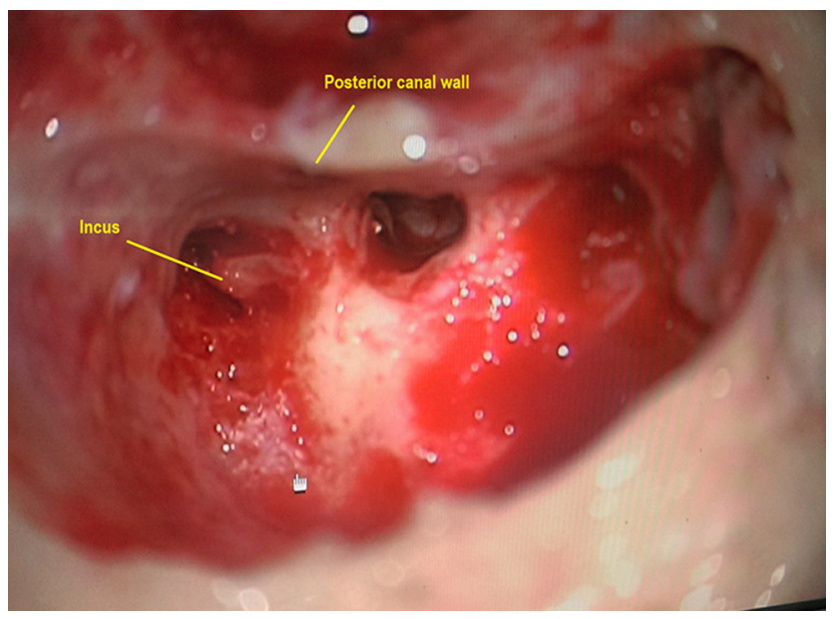

Fig. 2 Right facial recess approach. the EAC was done at the end of surgery. One case with Makek grade III was managed with resection of the facial nerve followed by primary (tension-free) anastomosis of the mastoid segment of the facial nerve (-Figs. 3-6).

\section{Postoperative Care}

Patients with facial nerve dysfunction following surgery were administered steroid in tapering dose (starting with equivalent of prednisolone $1 \mathrm{mg} / \mathrm{kg} / \mathrm{d}$ for 1 week and then tapered) as per department policy. Facial physiotherapy was also advised until complete eye closure was attained. As meticulous eye care was possible with proper patient training, tarsorrhaphy was not needed in any patient in present series ( - Table 1 ).

\section{Result}

Facial nerve rerouting was done in 4 out of 11 patients included in this series. Satisfactory outcomes in terms of facial nerve function were seen at 6-month follow-up in all these cases, including the one requiring nerve resection and primary anastomosis.

A patient operated via the extended facial recess approach with nerve decompression had grade IV function immediately postoperatively, which recovered to grade II on 6-month follow-up.

Facial nerve function in a patient with Fisch B glomus jugulare eroding the mastoid segment of the nerve (preoperative HB grade IV, Makek grade III) remained unchanged at 6-month follow-up.

Seven out of the 11 patients in this series did not merit a facial nerve rerouting based on their tumor extent/intent of surgery. All these patients had either unaltered/recovered (compared with preoperative) facial nerve function at 6 -month follow-up. Five out of these were operated by an infralabyrinthine approach (with/without neck exposure of major vessels). One patient each was operated via an extended facial recess approach and a conventional CWD mastoidectomy.

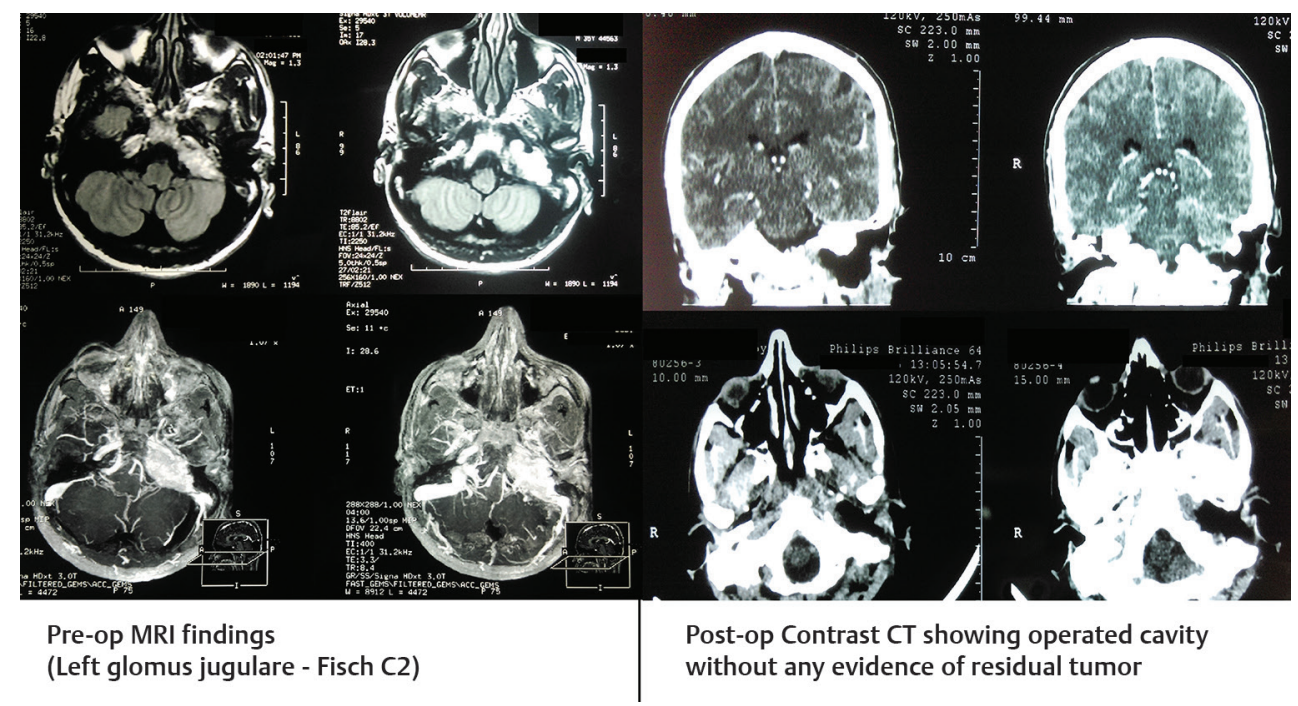

Fig. 3 Pre- and postoperative imaging findings. CT, computed tomography; MRI, magnetic resonance imaging. 


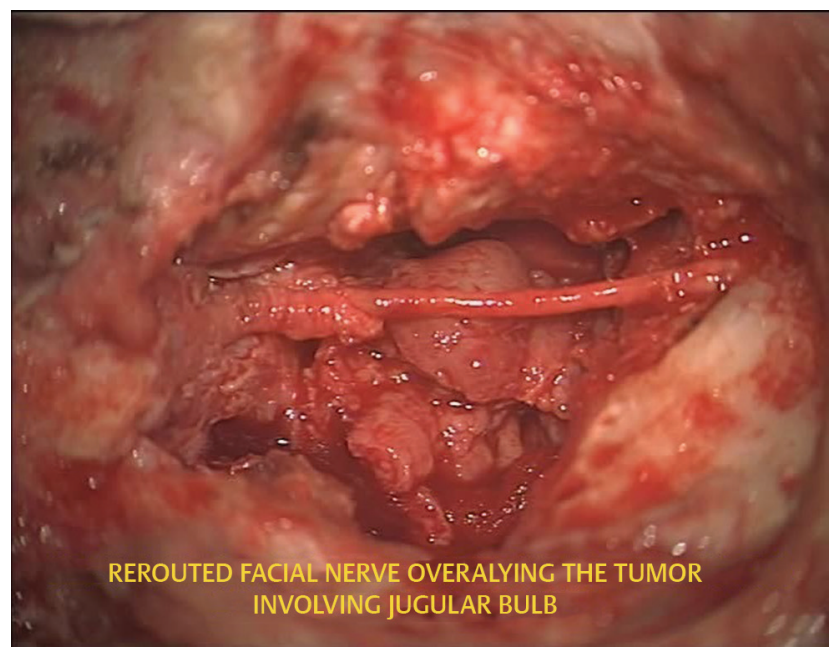

Fig. 4 Operative image: Left ITF Fisch A approach with nerve rerouting. ITF, infratemporal fossa.

Complete tumor excision was the aim of surgery for all cases of paraganglioma and schwannoma in this series. To avoid neurovascular compromise and/or because of obvious need for postoperative chemo/radiotherapy, a complete excision was not attempted in one case each of plasmacytoma, chordoma, and adenoma involving this complex region.

\section{Discussion}

Neuro-otologic procedures to access the petrous apex and jugular foramen have the obvious advantage of avoiding a conventional craniotomy, brain retraction, and their inherent complications obviously at the cost of hearing in certain cases. Although they offer a wide and shallow surgical field, the obvious challenge remains the management of the temporal bone contents, especially the internal carotid artery (ICA) and the facial nerve. ${ }^{5}$

The vertical mastoid segment of the facial nerve is centered on the jugular bulb, and it invariably comes in the access of trajectory while handling lesions in this area. Hence, it is desirable to either work around it or, if not possible, rerouting is needed before tumor is removed. ${ }^{6}$

Llorente et $\mathrm{al}^{7}$ found no difference in the surgical exposure attained or the tumor removal possible by mobilizing (rerouting) the temporal part of the facial nerve. Contradicting this are studies of cadaveric dissection by Von Doersten and Jackler, ${ }^{8}$ which quote a wider corridor for surgery and lesion removal as well as fewer recurrences ${ }^{9}$ on rerouting the facial nerve. It has also been suggested that removal of the bone around the jugular bulb and carotid canal cannot be done satisfactorily without facial nerve rerouting. ${ }^{1}$

The universal fact, however, remains that there is at least some transient deterioration in facial nerve function whenever its course within the temporal bone is manipulated surgically. Similar has been our experience following surgery when the nerve was rerouted.

Because of this, the aim of surgery has to be very clear before attempting rerouting of the nerve. Whenever possible to excise the lesion completely without rerouting, the

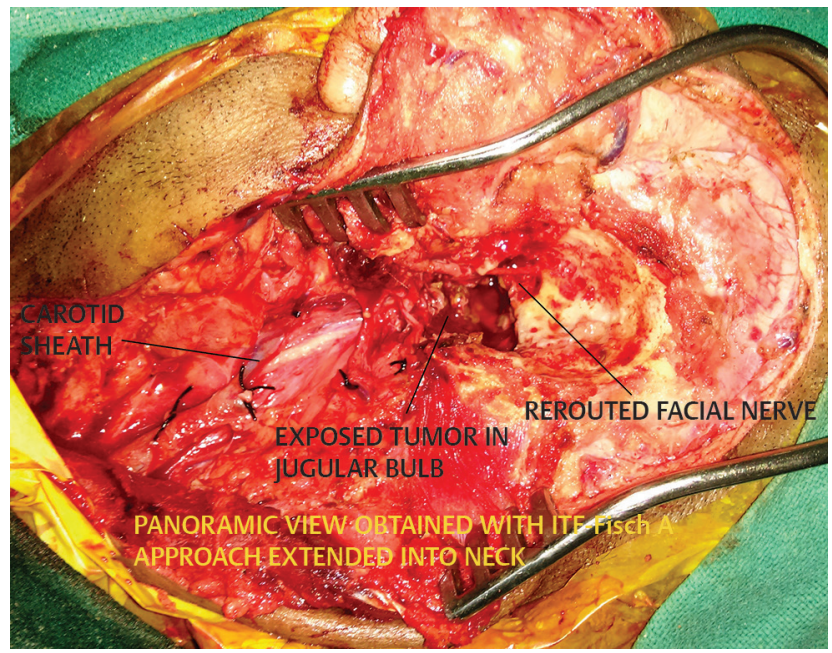

Fig. 5 Left ITF Fisch A approach after complete exposure. ITF, infratemporal fossa.

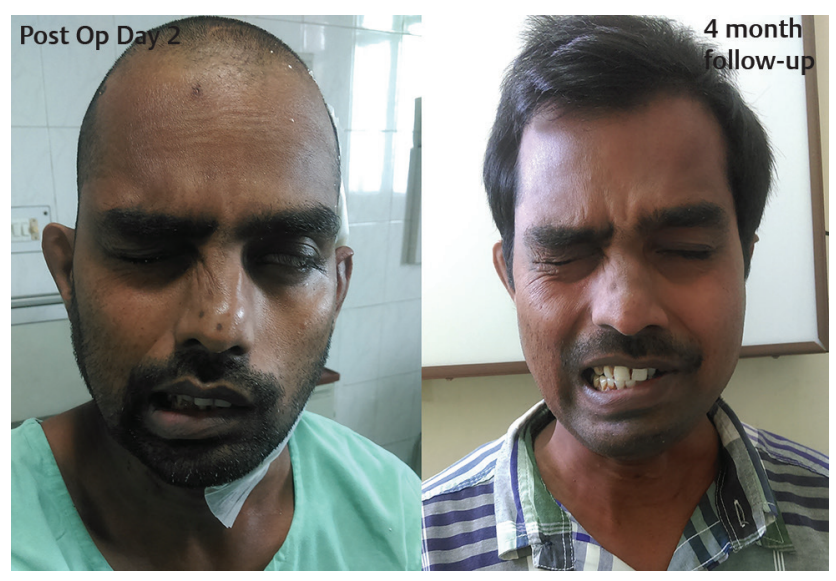

Fig. 6 Result following nerve rerouting.

approach should always be conservative. This is determined by the extent of the lesion, and this obviously is possible by a careful evaluation of the preoperative imaging (CT/MRI). Equally critical is the suspected tumor pathology, and whenever there is uncertainty preoperatively, an intraoperative frozen section helps make the surgical decision. This avoids not only unnecessary facial/lower cranial nerve dysfunction but also risk of injury to the major vascular structures (sigmoid sinus/jugular bulb/ internal jugular vein [IJV]/petrous ICA).

No attempt to reroute the facial nerve was done in four cases as the purpose of surgery was tissue diagnosis with maximal safe resection. The infralabyrinthine approach was chosen in five patients, and in select cases (3/3) complete tumor excision of tumor was possible without any added facial nerve deficits. The extended facial recess approach was used in a case that had involvement of the mastoid segment of the facial nerve, and following decompression of the involved segment, a complete tumor removal was not attempted. Rerouting of the nerve was done as part of the conventional infratemporal fossa Fisch A approach for complete tumor excision of jugular paragangliomas (all Fisch stage C2 or D1) in four cases and satisfactory (HB grade II or III) 
Table 1 Summary of observations and outcomes

\begin{tabular}{|c|c|c|c|c|c|c|c|c|c|c|c|}
\hline \multirow[t]{2}{*}{$\begin{array}{l}\text { Age/ } \\
\text { Sex }\end{array}$} & \multirow[t]{2}{*}{ Location } & \multirow[t]{2}{*}{$\begin{array}{l}\text { Preoperative } \\
\text { HB }\end{array}$} & \multirow[t]{2}{*}{$\begin{array}{l}\text { Aim of } \\
\text { surgery }\end{array}$} & \multirow[t]{2}{*}{$\begin{array}{l}\text { Surgical } \\
\text { approach }\end{array}$} & \multirow[t]{2}{*}{$\begin{array}{l}\text { Makek } \\
\text { grading }\end{array}$} & \multirow[t]{2}{*}{ Rerouting } & \multirow[t]{2}{*}{$\begin{array}{l}\text { Extent of } \\
\text { resection }\end{array}$} & \multirow[t]{2}{*}{$\begin{array}{l}\text { Final } \\
\text { diagnosis }\end{array}$} & \multicolumn{3}{|c|}{$\begin{array}{l}\text { Postoperative } \\
\text { facial nerve } \\
\text { function }\end{array}$} \\
\hline & & & & & & & & & $\begin{array}{l}\text { Day } \\
1\end{array}$ & $\begin{array}{l}3 \\
\text { mo }\end{array}$ & $\begin{array}{l}6 \\
\mathrm{mo}\end{array}$ \\
\hline $51 / M$ & $\begin{array}{l}\text { PA, CPA, } \\
C S, J F\end{array}$ & I & $\begin{array}{l}\text { Tissue } \\
\text { diagnosis, } \\
\text { max safe } \\
\text { resection }\end{array}$ & Infralabyrinthine & 1 & No & Subtotal & Plasmacytoma & 1 & - & - \\
\hline $37 / F$ & Fisch D1 & III-IV & $\begin{array}{l}\text { Total } \\
\text { excision }\end{array}$ & ITF-A & 1 & Long seg & Total & Paraganglioma & IV & IV & II-III \\
\hline $30 / \mathrm{M}$ & Fisch C1 & 1 & $\begin{array}{l}\text { Tissue } \\
\text { diagnosis, } \\
\text { max safe } \\
\text { resection }\end{array}$ & Infralabyrinthine & 1 & No & Subtotal & Paraganglioma & II & I & 1 \\
\hline $24 / M$ & $\begin{array}{l}J J F, C P A, \\
\text { PPS }\end{array}$ & 1 & $\begin{array}{l}\text { Tissue } \\
\text { diagnosis, } \\
\text { max safe } \\
\text { resection }\end{array}$ & $\begin{array}{l}\text { Infralabyrinthine } \\
+ \text { neck }\end{array}$ & 1 & No & Total & Chordoma & 1 & - & - \\
\hline $32 / \mathrm{M}$ & Fisch D1 & 1 & $\begin{array}{l}\text { Total } \\
\text { excision }\end{array}$ & ITF-A & 1 & Short seg & Total & Paraganglioma & IV & IV & $\|-I I I$ \\
\hline $30 / \mathrm{M}$ & Fisch D1 & I & $\begin{array}{l}\text { Total } \\
\text { excision }\end{array}$ & ITF-A & II & $\begin{array}{l}\text { Long seg } \\
+ \text { anasto }\end{array}$ & Total & Paraganglioma & IV & III & III \\
\hline $53 / F$ & Fisch C1 & 1 & $\begin{array}{l}\text { Total } \\
\text { excision }\end{array}$ & Infralabyrinthine & 1 & No & Total & Paraganglioma & 1 & - & - \\
\hline $61 / M$ & $\begin{array}{l}\mathrm{PA}, \mathrm{CPA}, \\
\mathrm{JF}\end{array}$ & II & $\begin{array}{l}\text { Tissue } \\
\text { diagnosis, } \\
\text { max safe } \\
\text { resection }\end{array}$ & $\begin{array}{l}\text { Extended facial } \\
\text { recess }\end{array}$ & II & No & Subtotal & Adenoma & IV & III & II \\
\hline $46 / F$ & Fisch B & IV & $\begin{array}{l}\text { Total } \\
\text { excision }\end{array}$ & $\begin{array}{l}\text { CWD } \\
\text { mastoidectomy }\end{array}$ & III & No & Total & Paraganglioma & IV & IV & IV \\
\hline $35 / M$ & Fisch C2 & 1 & $\begin{array}{l}\text { Total } \\
\text { excision }\end{array}$ & ITF-A & 1 & Long seg & Total & Paraganglioma & IV & IV & III \\
\hline $31 / \mathrm{M}$ & $\begin{array}{l}\text { JF, CPA, } \\
\text { PPS }\end{array}$ & I & $\begin{array}{l}\text { Total } \\
\text { excision }\end{array}$ & $\begin{array}{l}\text { Infralabyrinthine } \\
+ \text { neck }\end{array}$ & 1 & No & Total & Schwannoma & 1 & - & - \\
\hline
\end{tabular}

Abbreviations: CPA, cerebellopontine angle; CS, CWD, canal wall down; sinus; F, female; HB, House-Brackmann; ITF, infratemporal fossa; JF, jugular foramen; M, male; PA, petrous apex; PPS, parapharyngeal space; seg, segment.

function was regained by 6-month follow-up in all these. These results are consistent with some of the largest series reported in literature. ${ }^{1}$

The protocol for facial nerve management at this center includes meticulous care during surgery (avoid heat, minimal manipulation), postoperative steroids as previously mentioned, and eye care with facial physiotherapy until complete eye closure with minimal effort is attained.

\section{Conclusion}

The location and extent of lesion, preoperative neurovascular status, suspected tumor pathology, and intent of surgery based on the willingness of the patient for at least a transient facial dysfunction are the factors that determine the surgical approach to be adopted.A careful study of the preoperative imaging may allow us to obviate rerouting of the facial nerve to access the jugular foramen/petrous apex via inferior/ lateral approaches. Rerouting can also be avoided in select cases in which complete excision is not the aim of surgery However, whenever dictated by the lesion and with meticulous planning, surgical execution and postoperative care, favorable results in terms of not only facial nerve function but also tumor excision can be obtained with facial nerve rerouting Continuous team effort and recruitment of larger number of patients would allow us to maintain and even further improve the satisfactory results we have achieved for inferior and lateral approaches to the jugular foramen and petrous apex.

\section{Conflict of Interest}

None.

\section{References}

1 Bacciu A, Ait Mimoune H, D'Orazio F, Vitullo F, Russo A, Sanna M. Management of facial nerve in surgical treatment of previously untreated Fisch class $C$ tympanojugular paragangliomas: longterm results. J Neurol Surg B Skull Base 2014;75(1):1-7 
2 Inserra MM, Pfister M, Jackler RK. Anatomy involved in the jugular foramen approach for jugulotympanic paraganglioma resection. Neurosurg Focus 2004;17(2):E6

3 House JW, Brackmann DE. Facial nerve grading system. Otolaryngol Head Neck Surg 1985;93(2):146-147

4 Fisch U. Infratemporal fossa approach to tumours of the temporal bone and base of the skull.J Laryngol Otol 1978; 92(11):949-967

5 Russo A, Piccirillo E, De Donato G, Agarwal M, Sanna M. Anterior and posterior facial nerve rerouting: a comparative study. Skull Base 2003;13(3):123-130

6 Borba LA, Ale-Bark S, London C. Surgical treatment of glomus jugulare tumors without rerouting of the facial nerve: an infralabyrinthine approach. Neurosurg Focus 2004;17(2):E8
7 Llorente JL, Obeso S, López F, Rial JC, Coca A, Suárez C. Comparative results of infratemporal fossa approach with or without facial nerve rerouting in jugular fossa tumors. Eur Arch Otorhinolaryngol 2014;271(4):809-815

8 Von Doersten PG, Jackler RK. Anterior facial nerve rerouting in cranial base surgery: a comparison of three techniques. Otolaryngol Head Neck Surg 1996;115(1):82-88

9 Odat H, Shin SH, Odat MA, Alzoubi F. Facial nerve management in jugular paraganglioma surgery: a literature review. J Laryngol Otol 2016;130(3):219-224 